\title{
Analysis on Practical Teaching Reform of DSP Principle and Application Course from Electronic Design Contest
}

\author{
Honghui $\mathrm{Mu}^{1} \mathrm{a}^{*}$ and Ying Zhao ${ }^{2, \mathrm{~b}}$ \\ ${ }^{1,2}$ Changchun Sci-Tech University, Changchun 13000, China \\ amuhonghui@foxmail.com, b17920937@qq.com \\ * please mark the corresponding author with an asterisk
}

Keywords: DSP principle and application; Electronic design contest; Practical teaching reform

\begin{abstract}
The electronic design contest has played an important role in cultivating high-quality innovative talents, students can master many professional basic skills through the electronic design contest, which skills lay the foundation for future work in the electronic information industry. In this paper, we reform the practical course of DSP principle and application, which based on the competition, the aim is cultivate students' innovation ability and practice ability. Firstly, analyzed the DSP course present situation and problems. Secondly, reform and discussion are proposed based on CDIO theory, which include: experiment content reform, implementation process reform, multi-channel train and examination method reform. The reform had reached the purpose of training advanced applied talents.
\end{abstract}

\section{Introduction}

In recent years, the conception of applied talents training and credit system are implemented, which lead to time is limited but courses are more and more, so, how the education carry out become an important subject. The practice teaching is very important in the course of learning process, and with the development of the electronic information technology, the textbooks are used by many universities lag behind the new knowledge, and the knowledge of students studied in the classroom cannot meet the needs of new technologies. This point can be found from the application of new technology and new device that come from the title of previous electronic design contest. The electronic design competition is the process of transforming theoretical knowledge into practice, it provides a platform for colleges to implement teaching reform.

DSP principle and application is a comprehensive course with strong applicability and practicality, and with the development of microelectronics technology, the performance of the DSP chip is improved, but the cost is declining, the DSP chip become the basic chip gradually in power electronics, military, communications, automatic control and other fields. So if the college students master DSP technologies, it provide a powerful bargaining chip for future employment. Two parts are included by this course: the theory and the practice, the characteristic of the course is soft and hard are combined, a wide range of knowledge are covered, strong engineering practice abilities are required. MCU, EDA and other hardware are needed in the process of learning, the signal and system, digital signal processing, $\mathrm{C}$ programming language and assembly language are needed to master meanwhile. Therefore, how students to master this application technology in a limited time, and become wide caliber and strong applied talents are focused in this paper.

\section{The Position of DSP Curriculum Practice Teaching}

DSP principle and application course is opened by our school of information engineering, which is mainly for students of the electronic information science and technology, the technique and instrumentation of measurements. It is a comprehensive course with strong application ability, which is set up after the courses of single-chip microcomputer and the EDA. The total school hours are 48, which include the theory 32 hours and the experiment 16 hours. The DSP chip (digital signal 
processor) adopts Harvard structure, which has 6 buses. It can access data space and program space at the same time. The operation speed of DSP has faster than single-chip microcomputer, and can complete more complex computation and digital signal processing.

Practice is the only way to test the truth, the knowledge in the textbook only through practice teaching can deepen understanding and learn mastery. The kinds of DSP chip are wide varieties, which has substantial content, strong comprehensiveness, the students feel boring easily in the learning process, so theory and practice go on simultaneously is conducive to students mastery of classroom knowledge and comprehensive practice ability.

\section{The Present Situation and Main Problems of Practice Teaching}

With the increase of demand for talented who master the DSP technology in enterprise, the DSP technology is become the professional courses for many major engineering colleges and universities. The DSP course has many characteristics as follows: covering a wide range of knowledge, requiring high theoretical knowledge, requiring strong engineering practice ability, the chip update quickly and the teaching time is limited, the theory knowledge learning and practice ability cultivation of students are restricted by this characteristics, the problems existing of DSP in current practice teaching are mainly as follows:

Single Experiment. At present, there are eight in-class experiments as follows: Common instruction experiment, Switch test experiment, Event manager timer experiment, CPU timer experiment, External interrupt control experiment, A/D conversion and D/A conversion experiments. There are 2 hours for each experiment, the experiment contents are based on the CCS environment, the students only set some simple experimental configuration and amend program simply. The experiments all belong to the verification experiment. Due to the set of CCS software configuration is complex, so the software installation and configuration of the simulator mostly do by the teacher before the class, students only complete the experiment verification and program understanding in limited time. There are only a few students can master the project establishment and the $\mathrm{C}$ language program running, there are still a lot of students unfamiliar to CCS software development environment after the experiment.

Experiment Lack Innovation. The DSP experiment lack the innovation, there are belong basic module functions mostly, such as AD timer control, the timer configuration and so on, experiment cases are exist in various DSP experiment teaching material, which limited students' creativity and innovation [1]. The experimental properties is verification, experiment content simple, experiment results are known, the students only verify the validity of the knowledge simply, and do not master the performance of the chip and cultivate their innovation ability effectively.

Evaluation Mode Single. Curriculum evaluation can reflect the students' mastery of DSP technology. In recently, the experiment result accounts for $30 \%$ of the total grade, and evaluation mode include three aspects: experimental attendance, practical ability examination and test report. The assessment results are based on teacher assessment mainly, the actual results and spend time to complete the experiment are considered. This evaluation mode led to serious plagiarism in the lab reports, students who with strong hands-on skills tend to underperform due to poor reporting standards. Therefore, a single assessment method is not enough to judge students' achievements fairly and justly.

Attach Importance to the Guiding Role of Theory Course. A journey of a thousand miles begins with a single step, so any work carried out are need basis to be done well. This is especially true for electronic competitions, it is important to learn basic knowledge if you want to get good grades in the competition. Therefore, in the course of education for students, we must value theoretical teaching. In recent years, the content of the competition is the investigation of basic theory knowledge mainly, and it is related to the textbooks used by vocational schools at present closely. In 
terms of design, they are also based on the basic knowledge of the textbook, and the design of electronic technology is accomplished by applying these knowledge.

Therefore, it is very important to attach importance to the theory course guidance of DSP curriculum. Because of the wide variety of DSP chips, the universities should choose the content of the courses according to the students' employment orientation, then selected experimental equipment. The practical course is based on the theory, so the correct guidance of the theory course is the guarantee of completing the practical course. Firstly, the introduction part of the teacher should let the students establish the interest of the course as soon as possible, the teacher introduce the course from the nature, the content, the study method and the assessment method and so on. Secondly, the experimental content is interspersed into the theoretical process, for example, when explaining the DSP program space mapping, the data storage experiment content and configuration method can be introduced, then students can think after class that they can finish the experiment efficiently and make corresponding innovation and thinking in the effective time. Finally, when introducing the DSP software development process, the classroom can be moved to the laboratory, and let students have a certain perceptual knowledge of CCS software, focusing on the compilation, compilation and linking process of the software, then laying the foundation for the follow-up experiment courses.

Experiment Content Design and Development of CDIO Concept. The implementation of electronic competition can promote the improvement of students' ability in practice and innovation. In order to promote students practice and innovation ability better in the electronic competition, the school needs to reform its teaching system. And train students to learn from training to final innovation. Every student can build up a perfect knowledge network in the course of training, understand the content of the experiment, and improve the students' innovation ability through training.

In order to cultivate students' interest in learning, enhance students' innovative practice ability. Change the traditional experimental condition that multi-validation but less design, the content of teaching combines with CDIO (conception, design, implementation, and operation) teaching concept from easy to difficult, from light into deep and arrange experiments from step by step. It mainly include the application of digital signal processing technology, software and hardware design, algorithm verification and chip expansion, the key point is to integrate the practice and innovation ability into the conception, design, practice and operation. Because the operation of the practical courses is mainly attached to the experimental box, it is very important to choose the right and complete experimental project due to the restriction of hardware equipment.

For example, the experiment content of 16 hours is designed as follows: 6 hours confirmatory experiments, the main goal is to enable students to complete some basic verification experiments through the DSP experimental platform, then understood the main structure and function of each part of DSP chip through experiments. The students not only understand the experiment code, but also can modify the program after the experiment. 6 hours design experiments, the experimental requirements and the experiment purpose are gave to student, the students complete the choice of the experiment program and the design process of software and hardware themselves. Due to the high requirement of design experiment, so we can start it by modifying simple confirmatory experiments. Which method can develop the ability of analyze and solve problems independently. In addition, due to the limited time in the class, the experiment results can be done after class. 4 hours comprehensive experiment, which can be arranged after the course complete, the students according to their own interests and research needs to complete the design though conceive, design, implementation and operation.

In addition, in order to cultivate students' innovative consciousness and innovative ability in development, the course design and graduation design based on DSP platform can be established, and give students enough time to have a comprehensive and systematic understanding of DSP technology.

Practical teaching content based on CDIO concept as shown in table 1 [3]. 
The Implementation of CDIO Experiment Teaching Method. Firstly, the practical courses are arranged to be synchronized with the theory, the experimental courses are set up with the theoretical course, it is helpful for students to consolidate their theories. For example, when explaining the operation and configuration of CCS, then the teacher can cooperate with multimedia and teaching video to give students a more intuitive understanding, let students build up self-confidence and think "I can do it".

In the course of the experiment, adhering to the basic principle of "teachers as auxiliary and students as main", the teacher may assign the experimental purpose , the relevant experimental content, corresponding experimental procedures and methods before the experiment, other parts are done by students themselves, let students find problems and solve problems in experiments. Provide appropriate tips and instructions when students are unable to resolve which maximize increase the student's subjective initiative and the ability to solve problems.

Table 1 The practical teaching content of CDIO concept

\begin{tabular}{|c|c|c|}
\hline Stage & Required teaching content & Target \\
\hline $\begin{array}{c}\text { Conceive } \\
\mathrm{d}\end{array}$ & $\begin{array}{l}\text { DSP technology introduce, Engineering } \\
\text { background ( demand, functional analysis, } \\
\text { project plan, project management) , Basic } \\
\text { knowledge of DSP chip. }\end{array}$ & $\begin{array}{l}\text { Build students' interest } \\
\text { and confidence in } \\
\text { practice. }\end{array}$ \\
\hline Design & $\begin{array}{l}\text { Project requirements positioning; System } \\
\text { profile design and design analysis; Hardware } \\
\text { and software design. }\end{array}$ & 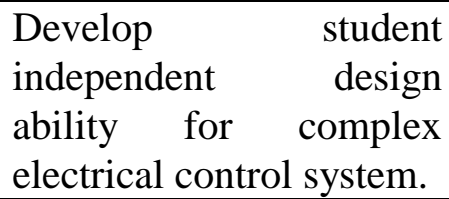 \\
\hline $\begin{array}{r}\text { Imple } \\
\text { n-tati }\end{array}$ & $\begin{array}{l}\text { Master software (Protel, CCS); DSP hardware } \\
\text { circuit board production and welding; C } \\
\text { language knowledge, code debugging method. } \\
\text { Software testing method; System integration, } \\
\text { testing and improvement. }\end{array}$ & $\begin{array}{l}\text { Train students on the } \\
\text { modular design ability } \\
\text { and team spirit of the } \\
\text { more complex electrical } \\
\text { control system. }\end{array}$ \\
\hline Operate & $\begin{array}{l}\text { The realization of products as commodities, } \\
\text { simulation and customer introduction and } \\
\text { communication; Solve man-made problems to } \\
\text { simulate product maintenance and repair; Add } \\
\text { new features for DSP products to simulate } \\
\text { product improvements and upgrades. }\end{array}$ & $\begin{array}{l}\text { Develop students' ability } \\
\text { to operate and maintain } \\
\text { the goods and } \\
\text { communicate } \\
\text { customers. }\end{array}$ \\
\hline
\end{tabular}

The related content of DSP system is designed as the topic of graduation thesis for students to choose. For example, "Design of a DSP based anti-theft system", "Design and implementation of FIR filter based on DSP", "Target tracking based on DSP system" and so on. Because the graduation design time is longer, students can not only learn the relevant theoretical knowledge of DSP, but also develop their ability to solve practical problems, then mastered the methods and steps of DSP system implementation and laid a solid foundation for the future graduation.

After the course is complete, students are grouped by teacher, then complete a simulation project, the specific operation is shown in Fig. 1. Firstly, let the students understand the requirements of the simulation project. Secondly, the task is conceived according to theoretical knowledge. According to the staff composition of the project, students are grouped and simulated role assignment, which include the project engineer, the software engineer, the hardware engineer and the test engineer. Students cooperate with each other. According to the role of the teacher under the guidance of the project design process planning, complete the design by means of various media. Thirdly, the implementation of the project, including circuit board welding, assembly and product debugging. In the end, the product is in operation stage, and the product is debugged and then operated and maintained. 


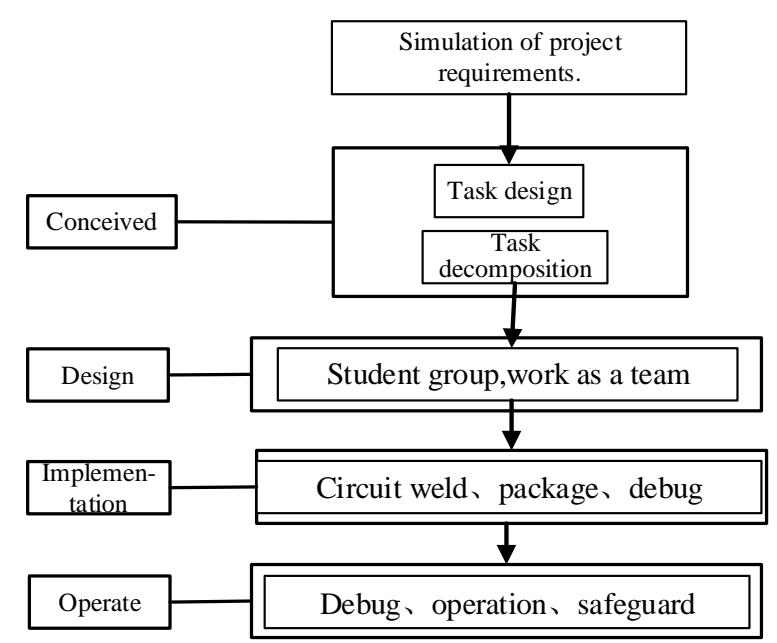

Figure 1. Finite The flow of simulate project execution

Multi-channel Cultivation of Student Engineering Application Ability. It is not enough to develop DSP technology in a limited class, it needs to be a continuation mechanism [4], it is necessary to extend it to open laboratory. Students can enter the laboratory though making an appointment online, then complete the experimental content that is not completed in class, select the open experimental project written by the teacher voluntarily, design an experimental project themselves. The teacher go to the laboratory and focus on answering questions every once in a while. This can not only provide students with an interest in learning resources, but also reflect the difference in personality cultivation principles.

To develop students' interest in electronic design, it is necessary arouse students' enthusiasm for learning, and carry out the second class activity vigorously among the students. Leading students to set up an electronic technology group, and invite experts and scholars to attend lectures on special topics. This method not only broadens students' horizons, but also promotes the exchange and learning between students. At the same time, the school can hold the electronic design competition in May and June every year, every students can attend if he interested. The campus competition is based on the model of national and provincial competitions. The students are required to complete the design, simulation, board and debugging until the finished product, and finally submit the design report. The campus competition let the students know the whole process of the design of the work and feel the atmosphere of the national competition in advance. The school electronic competition has accumulated practical experience and selected talents for the electronic contest in the whole province, it has also promoted the communication and level improvement among teachers.

Reform of Assessment Mechanism. The assessment is divided into two parts, one is the practice part and the second is the report writing section. The evaluation of practice link should consider the content conception, design, implementation and operation, which avoid the traditional practice link performance evaluation only consider the practice result and how much time it takes to complete the practice, in order to complete the training quickly, most students copy more and think less. Therefore, examine not too much emphasis on the result, but the whole process of attention to practice in the assessment link. This method give students more space to relax and think, and improve students' practical ability in essence.

The calculation of experimental results should be carried out in a comprehensive, just and objective principle, especially students' practical ability and solve problems ability. The practical assessment can be divided into experiment preview, classroom questioning, experimental result and innovation ability. The weight of each part is different, and the specific calculation formula is as follows: 


$$
D=\frac{\sum_{k=1}^{N} D_{i} x_{i}}{\sum_{k=1}^{N} x_{i}}
$$

$N$ is experiment times, $D_{i}$ is the results of the experiment, $x_{i}$ is the experimental weights of each part.

\section{Conclusion}

The arrival of the 21 st century has promoted the rapid development of science and technology, whole society has developed from the traditional single type social development to the present stage of diversification. In order to promote the rapid development of our country, the reform of education is imperative. The development of electronic competition helps to promote the reform of electronic information teaching in colleges and universities in China, and promote the successful work of vocational schools in China effectively, it can enrich students' amateur life and enhance their ability of practice and innovation.

\section{Acknowledgements}

This work was 2017 Higher Education Academy subject in Jilin province; Project approval no.:JGJX2017D282.

\section{References}

[1] J.F. Pan, F. Liu, Y. Niu, et al, Analysis on Teaching Reform of DSP Principle and Application Course for Ethnic Colleges: China Educational Technology \& Equipment, Vol. 3 (2015) No.22, p.118.

[2] C.Y. Zhou, B. Zhang, J.T. Pan, Research on Teaching Method and Evaluation Pattern of DSP Principle and Application: Journal of Electrical \& Electronic Education, Vol. 37 (2015) No.4, p.45.

[3] X. Ma, J. Wang, N. Xia, et al, Teaching mode exploration of DSP principle and application of electrical engineering major: China Modern Educational Equipment, Vol. 43 (2014) No.9, p.45.

[4] L.Y. Ling, Y.R. Huang, et al. Discussion on the Practical Teaching Reform of Electronic Information Major from Electronic Design Contest. ETMI 2016. (Shenzhen, China, October 30-31, 2016), Vol. 01 p.356.

[5] X.L. Zhang, X.H. Qiao, Discussion on the Practical Teaching Reform of Measurement and Control Technology and Instrument Specialty. Journal of Jiangsu University of Technology, Vol. 22 (2015) No.4, p.122. 